\title{
Influences of Intermittent Anaerobic Exercise Program on Physical Fitness and Plasma Lactate, Oxidant and Anti-oxidant Status in Smokers and Non-smokers Judo Players.
}

\author{
Bushra H. El-Zawahry*; Gamal A. Shawer** \\ and Mohamed Abd El-Rahman! \\ Physiology Department Faculty of Medicine (Girls)* and (Boys)** and Physical Education \\ Department Faculty of Education! Al-Azhar University-Cairo
}

\begin{abstract}
Background: There is evidence of smoking's negative impact and physical activity's positive impact on long-term health. However, evidences regarding the association between smoking and exercise activity and the independent effects of these factors on antioxidant defense are lacking. The aim of this study is to investigate the association between smoking and the intermittent anaerobic exercise on the physical fitness, oxidant and antioxidant status in Judo player.

Methods: Twenty male Judo player student from Department of Physical Education AlAzhar University were enrolled in the study. They were of 2 groups, Non-smokers (NS) and smokers (SM). Both groups were subjected to regular Judo training program (2 hours/day, 3 sessions/week for 12 weeks). Also, both groups were subjected to an effort test (running of submaximal intensity until exhaustion ) and record of the maximum oxygen capacity $\left(\mathrm{VO}_{2} \max \right)$ using an ergometric bicycle. Heart rate (HR), mean arterial blood pressure (MBP) were recorded and blood samples were taken pre and post-effort test for determination of malondialdehyde (MDA), total antioxidant capacity (TAC), uric acid (Ua) and lactate (La) in the plasma. Also the time to exhaustion was recorded during the effort test. These measures were performed pre and post the training program.

Results: At rest the pre-program data of SM showed significantly higher H.R., and plasma MDA , and significantly lower TAC with tendency to increase in MBP and La levels, and decrease in $\mathrm{VO}_{2} \max$, and Ua levels compared to NS. Before program and in response to acute exercise SM showed significantly higher H.R, MDA and La levels with significantly lower TAC, Ua and time to exhaustion compared to NS. On the other hand, after the program and in response to acute exercise, SM showed more pronounced significantly higher HR, MBP, MDA and $\mathrm{La}$ with significantly lower $\mathrm{VO}_{2}$ max, time to exhaustion and $\mathrm{TAC}$ with insignificant changes in the Ua compared to the NS that showed significant increase in the Ua levels with insignificant changes in the MDA, TAC and the La levels in response to acute exercise. In response to the training program, SM showed significantly higher HR, MBP, MDA and La levels, with significantly lower $\mathrm{VO}_{2}$ max, time to exhaustion, and $\mathrm{TAC}$, and insignificant changes in the Ua levels compared to NS.

Conclusion: We conclude that cigarette smoking has a significant detrimental effects on cardiovascular fitness, physical endurance, TAC and lipid peroxidation that all worsened by the intermittent anaerobic exercise. On the contrary, this type of training is beneficial in nonsmokers. Also we demonstrated that smoking prevent the beneficial effects of exercise, so smoking should be avoided in Judo players. Smokers should be given strong encouragement to stop smoking and to improve physical fitness.
\end{abstract}

\section{Introduction}

Cigarette smoking is associated epidemiologically with a high risk for various types of chronic illnesses including vascular disease (McNamara and Fitz Geraled, 2001). The underlying mechanisms of smoke-related severe damage to 
tissues and organs are still not completely understood; $\mathrm{O}$-and $\mathrm{N}$-derived free radicals are thought to play a major pathophysiological role (Polidori et al., 2003).

Cigarette smoke contains several types of toxic components. including carbon monoxide(CO), nicotine and benzo (a) pyrene (Raveendran et al., 2004). Super oxide, reactive oxygen species (ROS) and radicals are also component of cigarette smoke. One of the principal ROS produced in aerobic organism is $\mathrm{O}_{2}$, which is highly cytotoxic. However it may be possible to reduce smoke-induced damage by enhancing the protective defense system i.e increased levels of antioxidant enzymes (Gilks et al., 1998).

Physical exercise is known to have many beneficial effects on health. However, there is also evidence that free radical production increases during exercise especially intense physical exercise in unconditioned individuals , and that oxidative damage may occur in the muscle, liver, blood and perhaps other tissues (Margaritis et al., 2003). The free radicals produced during exhaustive exercise are very reactive chemical species and can readily lead to uncontrolled reactions, which may result in damage to DNA, proteins and lipids, causing molecular and cellular damage. So these individuals require stronger antioxidant defenses. Some of these defenses adapt with training (Groussard et al., 2003), or with proper antioxidant supplementation (Margaritis et al., 2003), but they can be overwhelmed by the higher production of ROS during intense physical exercise. There is evidence suggested that exercise intensity could influence the production of ROS and redox status in the body (Covas et al., 2002).

Judo training is a violent exercise which characterized by several series of 15 $30 \mathrm{sec}$. duration efforts with 10-15 sec. intervals between them (Finaud et al.,2006). Because these efforts are very intense and intervals are not long enough, ATP resynthesis by oxidative ways are unviable, and the effort becomes dependent on the glycolytic pathway that cause very high lactate accumulation (Tabata,1997).
Data concerning the acute effects of exercise on antioxidant enzyme defenses in human are controversial because of many types of exercise and experimental conditions adopted in previous researches, which do not allow for comparison between studies (Tauler et al., 2005).

However, evidences regarding the association between smoking and exercise activity and the independent effects of these factors on fitness and the antioxidant defense state are completely lacking, because in developed countries the athletes are less common to smoke. But in developing countries it is common to find an association between performing exercise and smoking specially in students of sport education faculties, who obliged to perform the physical activity in their practical lessons. This motivated us to study the effect of physical training ,Judo program, on lipid peroxidation represented by plasma level of MDA to reflect the oxidant status and the antioxidant state reflected by measurement of serum level of the TAC and uric acid in smokers and non-smokers Judo player students.

\section{Subjects and Methods}

The current study was conducted during the period of 3 months, between February and April 2006 on the $2^{\text {nd }}$ year male students of Department of Physical Education, Faculty of Education Al- Azhar University. Twenty volunteer male student were enrolled in this study, their (mean $\left.{ }_{-} \mathrm{SE}\right)$ anthropometric measurements as age, height and weight are shown in table (1). They were selected and assigned as 2 groups:

- Group (A): They were non smokers (NS). - Group (B): Smoker (SM), they smoke an average of 15 cigarettes /day for at least 3 years prior to the study.

All subjects were Judo practitioners had at least the brown belt, and all of them had to meet the following selected criteria (a) In a good health, with no known disease including diabetes, cancer or heart disease; (b) Not currently on a reducing diet regimen; (C) Not using medications known to affect the immune system; (d) Not using 
anabolic, vitamins or mineral supplements;

(e) Written consent was obtained from each subject.

- Both groups were subjected to regular Judo training program that consists of sessions of 2 hours/day (from 5-7 pm) for 3 sessions /week for 12 weeks. Each session was consisted of warming up for $15 \mathrm{~min}$., performing the training program for $95 \mathrm{~min}$. then cooling down for $10 \mathrm{~min}$.

-The training program were designed and supervised by a specialist.

\section{Experimental design}

At the beginning we recorded the height and weight for each subject, then each group was subjected to the following:

Recording of the physical fitness parameters, represented by measuring of:

a-Acute exercise, as an physical effort test, in the form of running of submaximal intensity until exhaustion, as it give the optimum reflection for acute aerobic exercise (Brunsgard, 2005). The time to exhaustion was recorded using stop watch. This test was done one day before beginning the training program (preprogram) and then repeated one day after the program i.e after 12 weeks.

b-Recording the H.R. from the mitral area ,using stethoscope, for each subject after 10 min of supine rest.

c-The systolic and diastolic blood pressures were measured using sphygmomano-meter. This was done for each subject after 5-10 min. of supine rest.

$d$ - $\boldsymbol{V O}_{2}$ max: It was measured indirectly by application of Astrand test for aerobic fitness from the H.R and the work load performed on the ergometric bicycle for 6 min. at submaximal $(70 \%)$ of the work load. Then the $\mathrm{VO}_{2} \max$ was measured by extrapolation using special table (Monogram) and expressed as litters/min.(Astrand and Rodhal, 1988). This test was done one day before beginning the training program (preprogram) and then repeated one day after the program.

\section{Blood Sampling}

Fasting blood samples from all subjects were withdrawn into EDTA containing tubes, from an antecubital vein with subjects in the seated position. Blood was centrifuged at $3000 \mathrm{~g}$ for $15 \mathrm{~min}$ at $4^{\circ} \mathrm{C}$., and the plasma was separated then stored at $-80^{\circ} \mathrm{C}$ until analysis.

- The HR, ABP and Blood samples were performed between 8 and 9 am before and within $10 \mathrm{~min}$. after the running test (i.e the pre and post-effort readings). This was done one day before beginning the Judo training program and repeated one day after finishing the program.

-The smoker subjects had been instructed to stop smoking for 2 hours before both the effort test and before each training session (Turner and Mc Nicol, 2002).

\section{Biochemical analysis}

-Plasma malondialdehyde (MDA) was measured to reflect the degree of lipid peroxidation, according to the method of Suttnar et al., (1997).

-Plasma uric acid (Ua) was measured according to the method of Williams et al. (1960).

-Plasma lactate was determined according to the method of Westgard et al.(1972).

-The plasma total antioxidant capacity (TAC) was measured spectrophotometrically according to the method of Koracevic et al., (2001) that based on measuring the capacity of the biological fluids to inhibit the production of thiobarbituric acid reactive substances (TBARS) from sodium benzoate under the influence of the free oxygen radicals derived from fenton's reaction.

\section{Statistical analysis}

Data were expressed as mean $\pm \mathrm{SE}$, statistical paired comparison of sequential results were preformed with the paired $t$ test for parametric comparisons of (pre) with post-effort data and (pre) with postprogram data of the same group. While, unpaired t-test was used when compared one group to the other group. P-value less than 0.05 was considered significant. 


\section{Results}

Table (1) demonstrated the anthropometric characteristics of both groups at base line. There were no significant differences among the two groups in the age, height, weight and VO2 max.

Table (2) demonstrated the differences in all parameters between smokers and non smokers at the base line (before beginning the program) and in response to the acute exercise (post-effort). At base line the smokers showed significantly higher H.R, and MDA levels $(\mathrm{P}<0.01)$ and significantly lower TAC $(\mathrm{P}<0.01)$. While the mean arterial blood pressure (MBP) and Ua and La levels showed insignificant differences between the two groups. On the other hand, in response to the acute exercise, the smokers showed significantly higher HR, MDA and $\mathrm{La}$ and significantly lower TAC and $\mathrm{Ua}$ levels in comparison to the non-smokers.

Table (3) demonstrated the differences in the different parameters between smokers and non-smokers in response to the acute exercise after performing the training program. The non smokers showed significant increase in the HR, MBP and the uric acid levels and insignificant changes in the plasma MDA, TAC and La levels in response to the acute exercise. However the smokers showed more pronounced increase in the HR, MBP, plasma MDA and La and more pronounced decrease in the TAC in response to acute exercise compared to nonsmokers. The Ua showed insignificant differences between the two groups in the pre-effort values and became significantly lower in smokers in the post- effort values.

Table (4) and Fig.(1) demonstrated the differences in the different parameters between smokers and nonsmokers in response to 12 weeks of Judo training program. In nonsmoker group the training program could significantly elevate the $\mathrm{VO}_{2} \max$ $(22.78 \%)$, the time to exhaustion $(66.5 \%)$ and the levels of TAC (45.96\%) and Ua (17.9\%), with tendency to lower the H.R ($4.54 \%), \mathrm{MBP}(-1.83 \%)$ and plasma $\mathrm{La}$ levels $(-4.85 \%)$. However the MDA levels showed insignificant changes compared to the resting preprogram values. On the other hand in the smokers the training program caused significant increase in MDA levels $(9.85 \%)$, tendency to increase in $\mathrm{MBP}$ $(2.62 \%)$ and insignificant changes in the remaining parameters compared to the resting pre-program values. In comparison to the non-smokers, the training program could aggrevate and increase the difference in smokers to show significantly higher HR (16.1\%), MBP (8\%), MDA (17.9\%) and La $(22.45 \%)$ and significantly lower $\mathrm{VO}_{2} \max$ (-25\%), time to exhaustion (52.9\%) and the TAC $(-42.9 \%)$ levels compared to the nonsmokers.

Table (1): Anthropometric characteristics of both groups at base line.

\begin{tabular}{|l|c|c|c|}
\hline & Non-smokers & Smokers & P-value \\
\hline Number & 10 & 10 & \\
\hline Age(years) & $18.5 \pm 0.23$ & $18.7 \pm 0.31$ & $\mathrm{P}>0.05$ \\
\hline Height $(\mathrm{cm})$ & $179.62 \pm 4.2$ & $177.83 \pm 4.5$ & $\mathrm{P}>0.05$ \\
\hline Weight $(\mathrm{Kg})$ & $83.4 \pm 2.6$ & $79.5 \pm 2.8$ & $\mathrm{P}>0.05$ \\
\hline VO2 max $(\mathrm{l} / \mathrm{min})$ & $3.16 \pm 0.18$ & $2.87 \pm 0.08$ & $\mathrm{P}>0.05$ \\
\hline
\end{tabular}


Table (2): Comparison between the different parameters of smokers and response to acute exercise before starting the program.

nonsmokers in

\begin{tabular}{|c|c|c|c|c|c|c|}
\hline & \multicolumn{2}{|c|}{$\begin{array}{c}\text { Non-Smokers (A) } \\
\mathrm{n}=10 \text { (Mean }+\mathrm{SE})\end{array}$} & \multicolumn{2}{c|}{$\begin{array}{c}\text { Smokers }(\mathrm{B}) \\
\mathrm{n}=10 \text { (Mean }+\mathrm{SE})\end{array}$} & \multicolumn{2}{c|}{ Difference between A\&B } \\
\hline & Pre-effort & Post-effort & Pre-effort & Post-effort & Pre-effort & Post-effort \\
\hline $\mathrm{H} . \mathrm{R}$ & $68.3 \pm 2.3$ & $167.2 \pm 3.2$ & $76.8 \pm 2.3$ & $178.8 \pm 4.3$ & $\mathrm{P}<0.01$ & $\mathrm{P}<0.025$ \\
$(\mathrm{beat} / \mathrm{min})$ & & $\mathrm{P}<0.0005$ & & $\mathrm{P}<0.0005$ & $12.45 \%$ & $6.9 \%$ \\
\hline $\mathrm{MBP}$ & $92.2 \pm 2.91$ & $109.8 \pm 4.2$ & $95.3 \pm 2.12$ & $110.8 \pm 3.1$ & $\mathrm{P}>0.05$ & $\mathrm{P}>0.05$ \\
$(\mathrm{~mm} \mathrm{Hg})$ & & $\mathrm{P}<0.0005$ & & $\mathrm{P}<0.0005$ & $3.36 \%$ & $0.91 \%$ \\
\hline $\mathrm{MDA}$ & $34.1 \pm 1.8$ & $39.2 \pm 2.1$ & $39.6 \pm 1.2$ & $47.8 \pm 1.5$ & $\mathrm{P}<0.01$ & $\mathrm{P}<0.0005$ \\
$(\mu \mathrm{mol} / \mathrm{l})$ & & $\mathrm{P}<0.05$ & & $\mathrm{P}<0.0005$ & $16.13 \%$ & $21.93 \%$ \\
\hline $\mathrm{T} \mathrm{AC}$ & $1.98 \pm 0.13$ & $1.82 \pm 0.18$ & $1.55 \pm 0.11$ & $1.35 \pm 0.17$ & $\mathrm{P}<0.01$ & $\mathrm{P}<0.0005-$ \\
$(\mathrm{m} \mathrm{mol} / \mathrm{l})$ & & $\mathrm{P}>0.05$ & & $\mathrm{P}>0.05$ & $-21.71 \%$ & $25.82 \%$ \\
\hline Uric acid & $5.02 \pm 0.21$ & $5.98 \pm 0.23$ & $4.58 \pm 0.41$ & $4.96+0.38$ & $\mathrm{P}>0.05-$ & $\mathrm{P}<0.05$ \\
$(\mathrm{mg} / \mathrm{dl})$ & & $\mathrm{P}<0.0005$ & & $\mathrm{P}>0.05$ & $8.76 \%$ & $17 \%$ \\
\hline Lactate & $1.03 \pm 0.08$ & $1.85 \pm 0.12$ & $1.13 \pm 0.06$ & $2.36 \pm 0.13$ & $\mathrm{P}>0.05$ & $\mathrm{P}<0.0005$ \\
$(\mathrm{~m} \mathrm{~mol} / \mathrm{l})$ & & $\mathrm{P}<0.0005$ & & $\mathrm{P}<0.0005$ & $9.7 \%$ & 27.56 \\
\hline
\end{tabular}

$-\mathrm{P}$ value less than 0.05 is considered significant.

Table (3): Comparison between the different parameters of smokers and nonsmokers in response to acute exercise after performing the program.

\begin{tabular}{|c|c|c|c|c|c|c|}
\hline \multirow{2}{*}{} & \multicolumn{2}{|c|}{$\begin{array}{c}\text { Non Smokers (A) } \\
\mathrm{n}=10(\text { Mean }+\mathrm{SE})\end{array}$} & Smokes (B) & $\mathrm{n}=10($ Mean \pm SE) & \multicolumn{2}{c|}{$\begin{array}{c}\text { Differance between }(\mathrm{A}) \& \\
(\mathrm{~B})\end{array}$} \\
\cline { 2 - 7 } & Pre-effort & Post-effort & Pre-effort & Post-effort & Pre-effort & Post-effort \\
\hline $\mathrm{H} . \mathrm{R}$ & $65.2 \pm 2.4$ & $148.5 \pm 3.8$ & $75.7 \pm 2.1$ & $174.3 \pm 7.2$ & $\mathrm{P}<0.0005$ & $\mathrm{P}<0.0005$ \\
$(\mathrm{beat} / \mathrm{min})$ & & $\mathrm{P}<0.0005$ & & $\mathrm{P}<0.0005$ & $16.1 \%$ & $17.3 \%$ \\
\hline $\mathrm{MBP}$ & $90.51 \pm 3.1$ & $105.6+4.2$ & $97.8 \pm 2.32$ & $114.7 \pm 2.53$ & $\mathrm{P}<0.05$ & $\mathrm{P}<0.05$ \\
$(\mathrm{mmHg})$ & & $\mathrm{P}<0.005$ & & $\mathrm{P}<0.0005$ & $8 \%$ & $8.8 \%$ \\
\hline $\mathrm{MDA}$ & $36.9 \pm 2.2$ & $41.8 \pm 2.3$ & $43.5 \pm 1.3$ & $49.6 \pm 2.4$ & $\mathrm{P}<0.01$ & $\mathrm{P}<0.0125$ \\
$(\mu \mathrm{mol} / \mathrm{l})$ & & $\mathrm{P}>0.05$ & & $\mathrm{P}<0.025$ & $17.9 \%$ & $18.66 \%$ \\
\hline $\mathrm{TAC}$ & $2.89 \pm 0.22$ & $2.69 \pm 0.21$ & $1.65 \pm 0.16$ & $1.23 \pm 0.11$ & $\mathrm{P}<0.0005$ & $\mathrm{P}<0.0005$ \\
$(\mathrm{~m} \mathrm{~mol} / \mathrm{l})$ & & $\mathrm{P}>0.05$ & & $\mathrm{P}<0.0005$ & $-42.9 \%$ & $-54.3 \%$ \\
\hline Uric acid & $5.92 \pm 0.48$ & $6.98+0.31$ & $5.53 \pm 0.52$ & $5.51 \pm 0.32$ & $\mathrm{P}>0.05$ & $\mathrm{P}<0.0005$ \\
$(\mathrm{mg} / \mathrm{dl})$ & & $\mathrm{P}<0.05$ & & $\mathrm{P}>0.05$ & $-6.59 \%$ & $21 \%$ \\
\hline Lactate & $0.98 \pm 0.08$ & $1.16 \pm 0.11$ & $1.20 \pm 0.12$ & $2.38 \pm 0.23$ & $\mathrm{P}<0.025$ & $\mathrm{P}<0.0005$ \\
$(\mathrm{~m} \mathrm{~mol} / \mathrm{l})$ & & $\mathrm{P}>0.05$ & & $\mathrm{P}<0.0005$ & $22.45 \%$ & $105 \%$ \\
\hline
\end{tabular}

-P value less than 0.05 is considered significant. 
Table (4): Comparison between the different parameters of smokers and nonsmokers in response to 12 weeks of Judo training program.

\begin{tabular}{|c|c|c|c|c|c|c|c|c|}
\hline & \multicolumn{3}{|c|}{$\begin{array}{c}\text { Non-Smokers (A) } \\
n=10(\text { Mean }+ \text { SE) }\end{array}$} & \multicolumn{3}{|c|}{$\begin{array}{c}\text { Smokers (B) } \\
\mathrm{n}=10(\text { Mean }+\mathrm{SE})\end{array}$} & \multicolumn{2}{|c|}{$\begin{array}{c}\text { Difference } \\
\text { Between A \& B }\end{array}$} \\
\hline & $\begin{array}{c}\text { Pre- } \\
\text { program }\end{array}$ & $\begin{array}{l}\text { Post- } \\
\text { program }\end{array}$ & $\begin{array}{l}\text { P-value\& } \\
\% \text { change }\end{array}$ & $\begin{array}{c}\text { Pre- } \\
\text { program }\end{array}$ & $\begin{array}{l}\text { Post- } \\
\text { program }\end{array}$ & $\begin{array}{l}\text { P-value\& } \\
\% \text { change }\end{array}$ & $\begin{array}{c}\text { Pre- } \\
\text { program }\end{array}$ & $\begin{array}{l}\text { Post- } \\
\text { program }\end{array}$ \\
\hline $\begin{array}{c}\text { H.R } \\
\text { (beat } / \mathrm{min} \text { ) }\end{array}$ & $68.3 \pm 2.3$ & $65.2 \pm 2.4$ & $\begin{array}{l}\mathrm{P}>0.05 \\
-4.54 \%\end{array}$ & $76.8 \pm 2.3$ & $75.7 \pm 2.1$ & $\begin{array}{l}\mathrm{P}>0.05 \\
-1.43 \%\end{array}$ & $\begin{array}{l}\mathrm{P}<0.01 \\
12.45 \%\end{array}$ & $\begin{array}{c}\mathrm{P}<0.0005 \\
16.1 \%\end{array}$ \\
\hline $\begin{array}{c}\mathrm{MBP} \\
(\mathrm{mmHg})\end{array}$ & $92.2 \pm 2.91$ & $90.51 \pm 3.1$ & $\begin{array}{l}\mathrm{P}>0.05 \\
-1.83 \%\end{array}$ & $95.3 \pm 2.12$ & $97.8 \pm 2.32$ & $\begin{array}{l}\mathrm{P}>0.05 \\
2.62 \%\end{array}$ & $\begin{array}{l}\mathrm{P}>0.05 \\
3.36 \%\end{array}$ & $\begin{array}{c}\mathrm{P}<0.05 \\
8 \%\end{array}$ \\
\hline $\begin{array}{c}\mathrm{VO}_{2} \max \\
(1 / \min )\end{array}$ & $3.16 \pm 0.18$ & $3.88 \pm 0.21$ & $\begin{array}{l}\mathrm{P}<0.01 \\
22.78 \%\end{array}$ & $2.87 \pm 0.08$ & $2.91 \pm 0.18$ & $\begin{array}{l}\mathrm{P}>0.05 \\
-1.39 \%\end{array}$ & $\begin{array}{l}\mathrm{P}>0.05- \\
9.18 \%\end{array}$ & $\begin{array}{c}\mathrm{P}<0.0005 \\
-25 \%\end{array}$ \\
\hline $\begin{array}{l}\text { Exhaus- } \\
\text { tion Time } \\
\text { (min) }\end{array}$ & $19.4 \pm 1.8$ & $32.3 \pm 2.4$ & $\begin{array}{c}\mathrm{P}<0.0005 \\
66.5 \%\end{array}$ & $13.5 \pm 1.3$ & 15.21 .5 & $\begin{array}{c}\mathrm{P}>0.05 \\
6.3 \%\end{array}$ & $\begin{array}{c}\mathrm{P}<0.01 \\
30.4 \%\end{array}$ & $\begin{array}{c}\mathrm{P}<0.0005 \\
52.9 \%\end{array}$ \\
\hline $\begin{array}{c}\text { MDA } \\
(\mu \mathrm{mol} / 1)\end{array}$ & $34.1 \pm 1.8$ & $36.9 \pm 2.2$ & $\begin{array}{l}\mathrm{P}>0.05 \\
8.21 \%\end{array}$ & $39.6 \pm 1.2$ & $43.5 \pm 1.3$ & $\begin{array}{l}\mathrm{P}<0.025 \\
9.85 \%\end{array}$ & $\begin{array}{l}\mathrm{P}<0.01 \\
16.13 \%\end{array}$ & $\begin{array}{c}\mathrm{P}<0.01 \\
17.9 \%\end{array}$ \\
\hline $\begin{array}{c}\mathrm{TAC} \\
(\mathrm{mmol} / \mathrm{l})\end{array}$ & $1.98 \pm 0.13$ & $2.89 \pm 0.22$ & $\begin{array}{c}\mathrm{P}<0.0005 \\
45.96 \%\end{array}$ & $1.55 \pm 0.11$ & $1.65 \pm 0.16$ & $\begin{array}{l}\mathrm{P}>0.05 \\
6.45 \%\end{array}$ & $\begin{array}{l}\mathrm{P}<0.01 \\
21.71 \%\end{array}$ & $\begin{array}{c}\mathrm{P}<0.0005 \\
-42.9 \%\end{array}$ \\
\hline $\begin{array}{l}\text { Uric acid } \\
(\mathrm{mg} / \mathrm{dl})\end{array}$ & $5.02 \pm 0.21$ & $5.92 \pm 0.48$ & $\begin{array}{l}\mathrm{P}<0.05 \\
17.90 \%\end{array}$ & $4.58 \pm 0.41$ & $5.53 \pm 0.52$ & $\begin{array}{l}\mathrm{P}>0.05 \\
20.74 \%\end{array}$ & $\begin{array}{l}\mathrm{P}>0.05 \\
-8.76 \%\end{array}$ & $\begin{array}{c}\mathrm{P}>0.05 \\
6.59 \%\end{array}$ \\
\hline $\begin{array}{l}\text { Lactate } \\
(\mathrm{mmol} / \mathrm{l})\end{array}$ & $1.03 \pm 0.08$ & $0.98 \pm 0.08$ & $\begin{array}{l}\mathrm{P}>0.05 \\
-4.85 \%\end{array}$ & $1.13 \pm 0.06$ & $1.20 \pm 0.12$ & $\begin{array}{l}\mathrm{P}>0.05 \\
6.19 \%\end{array}$ & $\begin{array}{l}\mathrm{P}>0.05 \\
9.7 \%\end{array}$ & $\begin{array}{l}\mathrm{P}<0.025 \\
22.45 \%\end{array}$ \\
\hline
\end{tabular}

-P value less than 0.05 is considered significant. 


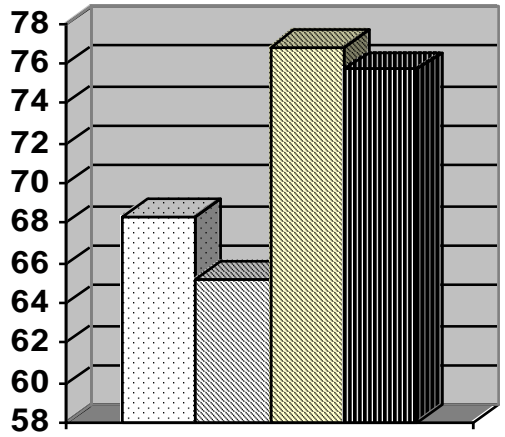

(A) HR(beat/min)

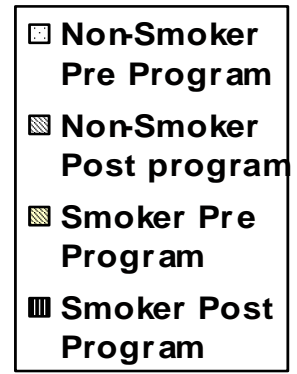

Program

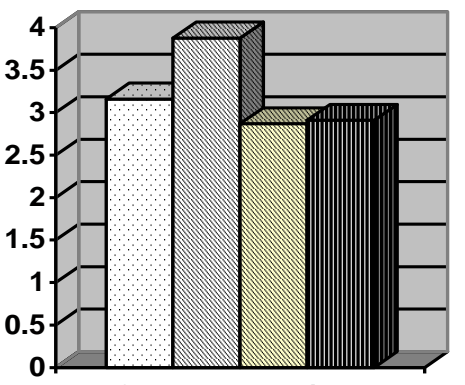

(C) VO2 $\max (1 / \mathrm{min})$

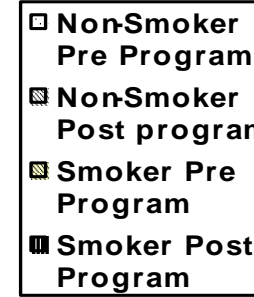

Program

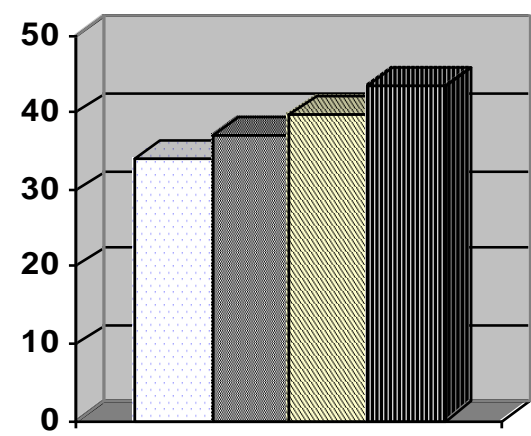

(E) MD A ( $\mu \mathrm{mol} / \mathrm{l})$

\begin{tabular}{|c|}
\hline$\square$ Non-Smoker \\
Pre Program \\
$\square$ Non-Smoker \\
Post program \\
ه Smoker Pre \\
Program \\
m Smoker Post \\
Program \\
\hline
\end{tabular}
Program

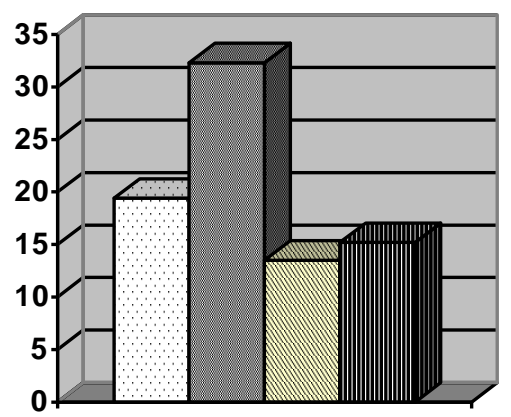

(D) Exhaustion tim(min)

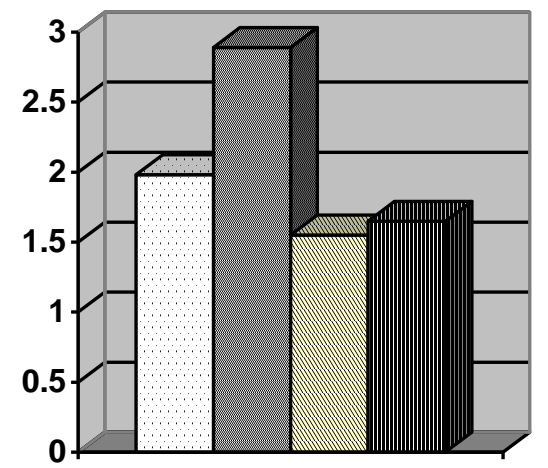

(F) TAC (mmol/l) $\square$ Non-Smoker Pre Program

Non-Smoker Post program

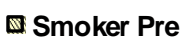
Program

III Smoker Post Program $\square$ Non-Smoker Pre Program 田 Non-Smoker Post program $\mathbb{Q}$ Smoker Pre Program m Il Smoker Post Program

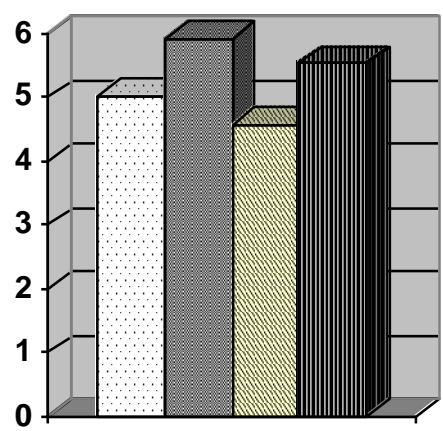

(G) Uric acid(mg/dl)

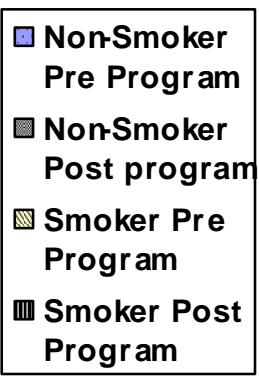

Program

Fig. (1) : Comparison between the different parameters of smokers and nonsmokers in response to 12 weeks of Judo training program. 


\section{Discussion}

Cigarette smoking is associated epidemiologically with a high risk for various types of chronic illnesses including atherosclerosis (McNamara and Fitz Gerald, 2001). The process of atherosclerosis is believed to be initiated by lipid peroxidation (Polidori et al., 2003).

Physical exercise is known to have many beneficial effects on health. However, data on the effects of acute and chronic exercise on antioxidant enzyme defences in humans are controversial and lacking in smokers.

Our results revealed that, at the base line (pre-program), during rest, smokers showed significantly higher H.R. and plasma MDA and significantly lower TAC levels with tendency to increase in MBP and lactate levels and decrease in $\mathrm{VO}_{2} \max$ and Ua levels compared to nonsmokers.

The increased H.R. in smokers may be related to the deficient oxygenation to the tissue that caused by carbon monoxide (CO) present in cigarette smoke (Polidori et al., 2003). Also the effect of nicotine is probably contributed to the significantly higher resting H.R. in smokers (Kobayashi et al., 2004). Turner and Mc Nicol (2002), also reported significant elevations in H.R and blood pressure after nicotine administration. Furthermore an animal study by Symons and Stebbins (1996) observed detrimental hemodynamic effect of nicotine on the cardiovascular system at rest, but during exercise these were minimized.

It has been reported that chronic smoking and acute exposure to cigarette smoke extract may alter endothelium dependent reactivity via the production of oxygen derived free radicals, due to the direct effect of nicotine on resistance arterioles, compliance arteries, smooth muscle cells, and ion channels in the cardiovascular system and in turn produce hypertension (Hanna, 2006). The smoker in the present study showed mild increase in the MBP compared to non-smokers. This may be due either to the short period of smoking, as the back years were only 3 years, or due to the stoppage of smoking 2 hours before the training as instructed in the study.

The observed decrease in $\mathrm{VO}_{2} \max$ and time to exhaustion in smokers are previously reported in several studies. Chatterjee et al., (1997) and Dyrstad et al., (2002) observed significantly lower $\mathrm{VO}_{2}$ max only in young age group of the smokers. Tchissambou et al (2004), reported that the subjects who were heavily dependent on nicotine had lower $\mathrm{VO}_{2} \max$ values and aerobic capacity than those less dependent. This may explain the decrease in the time to exhaustion and slower running observed in our study. It has been shown that smoking also affects work performance, specially endurance exercise (Surmen-Gur et al., 1999). Kobayashi et al., (2004), reported that $\mathrm{VO}_{2} \max$ and anaerobic threshold were acutely reduced in apparently healthy adult smokers immediately after smoking, as compared to five hour after smoking. Presumably because of elevated carbon monoxide and nicotine. This may explain the tendency to increase in the lactate levels in smokers in this study.

The significantly higher MDA and lower TAC levels observed in smokers in this work, may be due to one or more of the following reasons: First of all, smokers are prone to oxidation from inhalation of large numbers of gas-phase and other radicals giving rise to increased oxidative damage (Hanta et al., 2006). Second, depletion of plasma antioxidants, otherwise protecting against oxidative damage such as lipid peroxidation, that has consistently been observed among smokers (Lykkesfeldt et al., 2000). Third, smokers have been shown to have a lower intake of fruits and vegetables (Serdula et al., 1996), that known to protect against oxidative damage (La Vecchia and Tavani, 1998).

In agreement with these findings, smokers have been shown to have higher levels of lipid peroxidation compared with non-smokers, as measured by increased plasma thiobarbituric acid-reactive substances (TBARS), plasma and urinary concentrations of MDA, $F_{2}$-isoprostanes and 


\section{Bushra H. El-Zawahry et al}

conjugated dienes (Block et al., 2002). However, higher levels of lipid peroxidation among smokers in the study of Block et al. (2002) and several previous studies could in fact primarily be a secondary effect of the poorer antioxidant status also found in smokers. Block's group also found an inverse correlation between plasma ascorbic acid and MDA (Block et al, 2002). This further supports the link between antioxidant status and MDA. However Lykkesfeldt et al. (2004), suggested that lipid peroxidation is induced by smoking per se. While poor antioxidant status presumably also affect lipid peroxidation, it is only partly responsible for the increased level found in smokers in general.

Goraca and Skibska (2005) studied the relationship between lipid peroxidation and total plasma antioxidant capacity (TAC) in healthy smoking and nonsmoking subjects. They found that, smokers have significantly lower TAC and significantly higher TBARS than nonsmokers. They also found significantly lower plasma concentrations of non enzymatic antioxidants (alpha-tochopherol, beta-carotene and ascorbic acid) in chronic smokers compared to nonsmokers. In the same study, in vitro addition of ascorbic acid, or trolox to plasma samples from smokers, significantly increased their TAC. Also, it has previously been reported that plasma exposure to gas-phase cigarette smoke caused depletion of carotenoides, Vitamin $\mathrm{C}$, uric acid and $\alpha$-tocopherol, and induction of lipid peroxidation in vitro (Polidori et al., 2003).

In the present study and in response to acute exercise, both groups showed similar response but smokers showed more pronounced elevation of the HR and levels of MDA and lactate, and more pronounced reduction in TAC levels and the time taken to reach exhaustion compared to nonsmokers.

This similarity of the exercise HR responses in the nonsmokers and smokers at equivalent stress levels, in response to acute exercise both in pre-program and post-program periods, suggests that the cardiovascular system was fully and equally taxed in both groups in terms of stroke volume. This indicates that the arteriovenous difference was smaller and the $\mathrm{O}_{2}$ extraction reduced in smokers. This in agreement with the study of Kobayashi $e t$ al. (2004) who found similarity in HR responses of smoker and non-smokers to sub-maximal and maximal exercise but the $\mathrm{O}_{2}$ pulse was always lower in smokers. Also the return of HR to resting levels after exercise was slower in chronic smokers. This may be related to the chronotropic and inotropic effects of catecholamines mobilized by nicotine absorbed from cigarette smoke (Tchissambou et al., 2004). This may explain also the decreased time to exhaustion and the slower performance observed in smokers which may be also due to the progressive increase in lactate levels in smokers by exercise. However in response to the training program the nonsmokers showed lower resting H.R and MBP compared to smoker. This indicates the good adaptation response to training program in nonsmokers and failure of this response in smokers. Our results are in line with the study of Godsland et al. (1998).

The elevated lactate levels in response to acute exercise specially in smokers in the present study, agree with the results reported by many studies (Surmen-Gur et al., 1999 and kobayashi et al., 2004). According to kobayashi group, the more intense the exercise, the more lactate is produced and taken up by the working muscle. This was more pronounced in smokers. Smokers have been shown to have a reduced anaerobic threshold, as a consequence of increased anaerobiosis and reduced tissue $\mathrm{PH}$ and an increase in $\mathrm{CO}_{2}$ output via the bicarbonate buffer system (Hemila et al.,2006).

The increased lipid peroxidation and decreased anitoxidant activity in response to acute exercise in the pre-program period is reported by several studies Surmen-Gur et al., 1999, Groussard et al., 2003 and Demirbag et al., 2006). According to these data, the principal factor responsible for oxidative damage during exercise is the increase in the oxygen consumption. However, in the post-program period and in response to acute exercise, the resting (preeffort) value showed insignificant changes 
in non smokers but significantly elevated in smokers and progressively increased following acute exercise. This may be due to in addition to the increase in oxygen consumption already found in smokers, other theoretical factors such as acidosis, catecholamine auto-oxidation and ischemiareperfusion syndrome, may also be operative during short-term supramaximal anaerobic exercise (Franchini et al., 2003) that is repeated during and throughout the period of Judo training in our study. This may explain the failure of adaptation of cardio-respiratory systems in smokers in the post-program period, compared to preprogram values, as the nonsmokers showed lower values of H.R and MBP in both resting and in response to acute exercise, but smokers still had higher values. This is in agreement with the study of Bernaards et al. (2003).

The slower performance and early exhaustion observed in smokers in our study in response to acute exercise in both the pre-program and post-program period, agree with the study of Hemila et al. (2006). They found that the young male smokers ran slower and the exercise endurance time on the treadmill protocol was significantly longer in the nonsmokers. But the aerobic performance $\left(\mathrm{VO}_{2} \max \right)$ was affected only during highintensity aerobic exercise in smokers.

Groussard et al. (2003), hypothesized that short-term supramaximal anaerobic exercise (30 second Wingate test) could induce an oxidative stress. But they observed that, the recovery of exercise was associated with a significant increase in lipid radical production, as well as with decrease in the erythrocyte reduced glutathione (GSH) level and superoxide dysmutase (SOD) activity. Also they suggested that, the paradoxical decrease in plasma TBARS which was correlated with the peak power developed during the Wingate test, strongly suggests that such exercise stimulate the elimination of MDA. This in line with the effect of 3 month training program in non-smokers in our result. However the progressive increase in MDA and decrease in TAC in smokers is probably due to the action of $\mathrm{CO}$ and nicotine and other superoxides and other reactive oxygen species (ROS) found in cigarette smoke, together with the oxidative stress caused by the acute exercise that cause oxidative damage and disturbance in the oxidant/antioxidant ratio. (Tsuchiya et $a l ., 2002$ and Ozbay and Dulger 2002). This is supported by the findings of Demirbag et al., (2006) who demonstrated that treadmill exercise test increases oxidants, decreases TAC and vitamin $\mathrm{C}$, but this stress is not enough to produce DNA damage. While Covas et al. (2005), found that antioxidant enzyme activities in post-exercise values were significantly higher than those of preexercise values, in saliva of elite Judoists.

In response to the training program our findings regarding the increase in TAC in non-smokers were in accordance to the findings of (Chevion et al.,2003). Also, an animal study investigated the effect of intermittent anaerobic exercise program on the tissue antioxidant capacity and lipid peroxidation, found that this type of exercise led to a higher TAC in muscle, heart and brain in mouse (Qiao et al., 2006).

However the data about the acute and chronic effect of exercise on TAC and lipid peroxidation in smokers are completely lacking. But the decrease in TAC and the increase in MDA levels in response to acute exercise and non-improvement in their levels by the training program were expected in smokers, probably due to the oxidative stress caused by the gas phase in cigarette smoke together with the oxidative stress caused by the intermittent anaerobic exercise of Judo training. Both can cause oxidative damage, disturbance in the oxidant/antioxidant ratio and decreasein the anaerobic threshold (Ozbay and Dulger 2002, and Goraca and Skibska, 2005).This may also explain the decreased time to exhaustion and $\mathrm{VO}_{2} \max$ and the elevation in lactate levels in smokers in post-program readings.

Uric acid (Ua) has been identified as the most important non-enzymatic antioxidant present in human body fluids (Tsuzita et al.,2006).

In the present study, the plasma Ua showed significant increase in non smokers 


\section{Bushra H. El-Zawahry et al}

in response to acute exercise both pre and post-program compared to the smokers that showed insignificant changes. Also, the training program caused significant elevation in the basal level (pre-effort) of plasma Ua in non-smokers compared to smokers. These findings are in agreement with that of Chevion et al. (2003) and Demirbag et al. (2006) who found significant increase in plasma uric acid after acute exercise due presumably to increases in the metabolic rate and consequent pyrimidine nucleotide metabolism. However Tsuzita et al. (2006) suggested that, the increase in adenine nucleotide degradation and lactic acid production, as well as a release of noradrenalin caused by exercise, contribute to increases in plasma level of urate, as well as decreases in urinary excretion of Ua. While the increase in Ua level by the training program may be due to the repeated effect of anaerobic exercise throughout the period of Judo training, as it has been reported that Wingate test (30 sec-sprint anaerobic exercise), led to increase in plasma Ua and ascorbic acid concentrations. (Groussard et al., 2003). On the other hand, the tendency to decrease in Ua observed in smokers in response to both acute and chronic exercise in the present study is in agreement with the study of Tsuchiya et al.( 2002), who reported that smoking a single cigarette decreases plasma levels of Ua.

On the contrary, it has been suggested that there is no association between smoking and plasma uric acid levels (Stathis et al., 2005).

Frei et al. (1999), found that exposure of plasma to cigarette smoke caused oxidation of plasma protein thiols and albumin-bound bilirubin, where as uric acid is not consumed at significant rates.

\section{Conclusion}

We conclude that cigarette smoking has a significant detrimental effect on cardiovascular and physical fitness, indicated by decreased response to adaptation of $\mathrm{HR}, \mathrm{MBP}$, reduced $\mathrm{VO}_{2}$ max and decreased time to exhaustion in response to both intermittent anaerobic Judo program and to acute aerobic exercise. This probably related to decreased $\mathrm{O}_{2}$ carrying capacity and decreased plasma lactate threshold in smokers. Also smoking per se led to lipid peroxidation and lowered the total antioxidant capacity and exacerbated them in association to intermittent anaerobic exercise. On the contrary this type of exercise is beneficial for physical fitness and antioxidant defenses in nonsmokers .Thus our finding indicated that smoking is a detriment to physical fitness even among relatively young fit individuals, as it prevented the beneficial effects of exercise. So smoking should be avoided in Judo players and smokers should be given strong encouragement to stop smoking to improve their physical fitness.

\section{References}

1. Astrand $P$ and Rodhal K(1988): Textbook of work physiology,Mcgrow-Hill,New York.P 305-9.

2. Bernaared C, Twisk R, Mechelen V and Snel J (2003): A longitudinal study on smoking in relationship to fitness and heart rate response. Med. Sci. Sports Exerc., 35:793-9.

3. Block G, Dietrich M, Norkus P, Caan B and Packer L (2002): Factors associated with oxidative stress in human populations. Am. J. Epidemiol., 156, 274-85.

4. Brunsgard H (2005): Physical activity and modulation of low systemic low level infl-ammation. J. Leukoc. Biol., 78 (4): 819-35.

5. Chatterjee $S$, Dey $\mathbf{K}$ and Nag $K$ (1997): Maximum oxygen uptake capacity of smokers of different age groups. Jpn. J. Physiol., 37(5): 837-50.

6. Chevion S, Moran D, Heled Y, Shani Y and Epstein Y (2003): Plasma antioxidants status and cell injury after severe physical exercise. Bioch. Physiol. 100 (9) 5119-23.

7. Covas M, Elosua R, Fito M, Coca $L$ and Marrugat J (2002): Relationship between Physical activity and oxidative stress biomarkers. Med. Sci. Sports Exer., 34(5): 814-19. 
8. Covas L, Arpinar $\mathbf{P}$ and yurdakoc K (2005): Possible interaction between antio-xidant enzymes and free sialic acid in saliva : a preliminary study on elite Judoists. Int. J. Sports Med., 26 (10):832-5.

9. Demirbag R, Yilmaz R, Guzel S, Celik $H$ and Ozcan E (2006): Effect of treadmill exercise test on oxidative/antioxidative parameters. Anadolu Kardiyol. Derg., 6:135-40.

10. Dyrstad s, Aandstad A and Hallen J (2002): Aerobic fitness in young Norwegian men.Scand. J. Med. Sci. Sports, 15 (5):298-303.

11. Finaud J, Degoutte F, Durand D and Filaire E (2006): Competition and food restriction effects on oxidative stress in Judo. Int. J. Sports Med., 27(10): 83441.

12. Franchini E, Takito Y, Nakamura $F$ and Kiss $P$ (2003): Effect of recovery type after a Judo combat on blood lactate removal and on performance in an intermittent anaerobic task. J. Sports Med. Phys. Fitness, 43: 424-31.

13. Frei B, Forte T, Ames B and Cross C (1999): Gas Phase oxidants of cigarette smoke induce lipid peroxidation and changes in lipoprotein properties in human blood. Protective effect of ascorbic acid. Biochem. J., 277, 133-8.

14. Gilks B, Price $\mathbf{K}$ and Wright J (1998): Antioxidant gene expression in rat lung after exposure to cigarette smoke, Am. J. Pathol,. 152: 269-8.

15. Godsland I, Leyva F, Walton C and Stevenson $J$ (1998): Association of smoking, alcohol and physical activity with risk factors for coronary heart disease. J. Int. Med., 244(1): 33-41.

16. Goraca A and Skibska B (2005): Plasma antioxidants status in healthy smoking and non-smoking men. Bratisl. Lek. Listy., 106 (10): 301-6.

17. Groussard C, Machefer G, Rannou F, Faure $H$ and Gratas A (2003): Physical Fitness and plasma non-enzymatic status at rest and after a Wingate test. Can J. Appl. Physiol., 28(1): 79-92.

18. Hanna S (2006): Nicotine effect on cardiovascular system and ion Channels. J. Cardiovasc. Pharmacol. 47(3): 348-58.

19. Hanta I., Koabas A, Kuleci S and Seydaoglu G, (2006): Oxidant-antioxidant balance in patient with COPD. Lung., 184(2): 51-5.

20. Hemila H, Kaprio J, Albanes D and Virtamo J (2006): Physical activity and the risk of pneumonia in male smokers administered vitamin $\mathrm{E}$ and beta carotene. Int. J. Sports. Med., 27 (4):336-41.

21. Kobayashi Y, Takeuchi T, Hosoi T and Loeppky A (2004): Effect of habitual smoking on cardiorespiratory responses to submoximal exercise. J. Physiol. Anthropol. App. Human Sci., 23 (5): 163-9.

22. Koracevic D, Djordjevic V, Andrejevic $S$, and Cosic V (2001): Method for measu-rement of total antioxidant activity in human fluids. J. Clin. Pathol., 54: 356-61.

23. La Vecchia $C$ and Tavant A (1998): Fruit and vegetables, and human cancer. Eur. J. Cancer. Prev., 7, 3-8.

24. Lykkesfeldt J Christen S Chang H Jacob A and Ames N (2000): Ascorbate is depleted by smoking and repleted by moderate supplementation. Am. J. Clin. Nutr., 71, 530-6.

25. Lykkesfeldt J, Viscovich $M$ and Poulsen H (2004): Plasma malondialdehyde is induced by smoking. British. J. Nut. 92:203-6.

26. Margaritis I, Rousseau A, Richard $M$ and Favier A (2003): Antioxidant supplementation and tapering exercise improve antioxidant response. J. A. coll. Nut., 22(2): 147-56.

27. McNamara $P$ and Fitz Gerald A (2001): $\quad$ Smoking-induced Vascular disease. Circ. Res ., 89:563-65.

28. Ozbay B and Dulger H (2002): Lipid peroxidation and antioxidant enzymes in Turkish population: Relation to age, gender, exercise 
and smoking. Tohoku. J. Exp. Med., 197,119-24.

29. Polidori M, Mecocci P, Stahl W and Sies H (2003): Cigarette smoking cessation increases plasma levels of several antioxidant and improves resistance towards oxid-ative challenge. British. J.Nut., 90, 147-50.

30. Qiao D, Hou $\mathbf{L}$ and Liu $X$ (2006): Influence of intermittent anaerobic exercise on mouse physical endurance and antioxidant components. British. Sport. Med., 40:214-18.

31. Raveendran $M$ Senthil $D$ and Utama B (2004): Cigarette suppresses the expression of $\mathrm{P} 4 \mathrm{H}$ alpha and vascular collagen production. Biochem. Biophys. Res. Commun., 323: 592-8.

32. Serdula M, Byers T, Mokdad A, Simoes E and Coates J (1996): The association between fruit and vegetable intake and chronic disease risk factors. Epidemiol., 7, 161-5.

33. Stathis G,Carey F and Snow J (2005):The influence of allopurinol on urinary purine loss after repeated sprint exercise in men. Metabol., 54 (10):1269-75.

34. Surmen-Gur E, Ozturk E, Gur $H$ and Tuncel $P$ (1999): Effect of vitamin $\mathrm{E}$ supplementation on post-exercise plasma lipid peroxidation and blood antioxidant status in smokers Eur. J. Appl. Physiol., 79: 472-8.

35. Suttnar J, Cermak J and Dyr E (1997): Solid phase extraction in malondialdehyde analysis.Anal. Biochem., 249:20-3.

36. Symons $\mathbf{J}$ and Stebbins $\mathbf{C}$ (1996): Hemodynamic and regional blood flow responses to nicotine at rest and during exe- rcise. Med. Sci. Sports Exerc. 28: 457-67.

37. Tabata I (1997): Metabolic profile of high intensity intermittent exercise. Med. Sci. Sports Exer., 29:390-5.

38. Tauler P, Aguilo A, Guix P, Junenez F and Pons A. (2005): Pre-exercise antioxidant enzyme activities determine the antioxidant enzyme erythrocyte response to exercise. J. sports Sci., 23 (1): 5-13.

39. Tchissambou P, Massamba A, Babela $R$ and Senga $P$ (2004): The effects of smoking and the degree of nicotine dependence on aerobic capacity in sport-smen. Rev. Mal. Respir., 21 (1): 59-66.

40. Tsuchiya M, Asada A, Sato E and Inoue $M$ (2002): Smoking a single cigarette rapidly reduces combined concentrations of nitrate, nitrite and antioxidants in plasma. Circ., 105:1155-65.

41. Tsuzita J, Oku Y and Yamamoto $T$ (2006): Plasma concentration and urinary excretion of purine bases (uricacid, hypox-anthine and xanthine) and oxypurinol after vigorous exercise. Metabol., 55 (1): 103-7.

42. Turner $J$ and Mc Nicol $M$ (2002): The effects of nicotine and carbon monoxide on exercise performance in normal subjects. Respir. Med., 87: 427-31.

43. Westgard J, Lahmeyer B and Birnbaum M (1972): Use of the automatic analyzer in direct determination of lactic acid in plasma. Clin. Chem., 18: 1334-5.

44. Williams L, Bousock Y and Zak B (1960): Colorimetric technique for determ-ination of uric acid. Anal. Chem., 32 : 1883-5. 
تأثير برنامج التمرينات الرياضية اللاهوائية المتقطعة على اللياقة البدنية

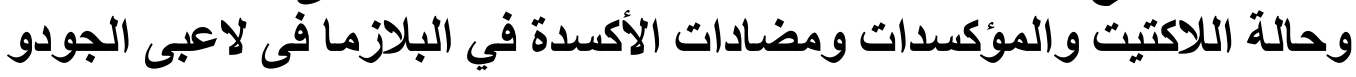
المدخنين وغير المدخنين

بشرى حسن الظواهرى* وجمال أحمد شاور ** ومحمد عبد الرحمن!

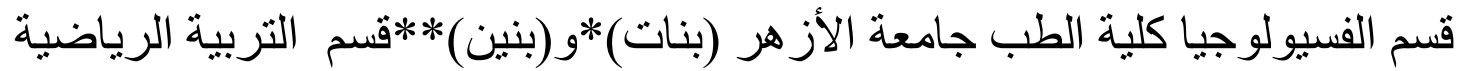

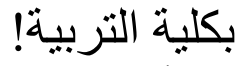

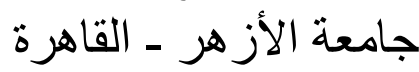

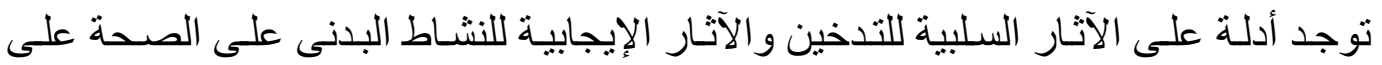

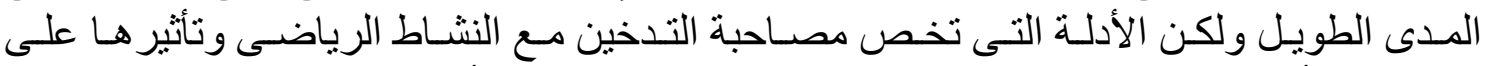

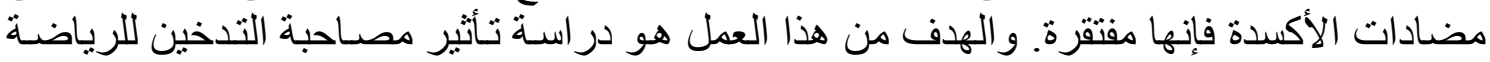

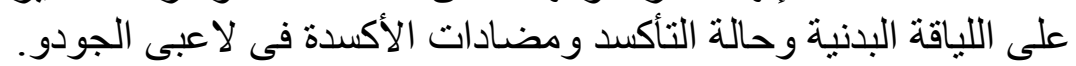

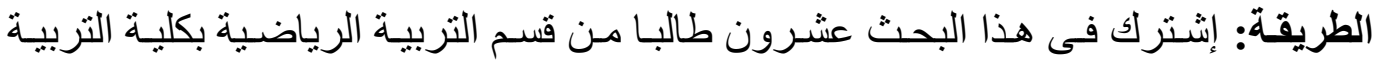

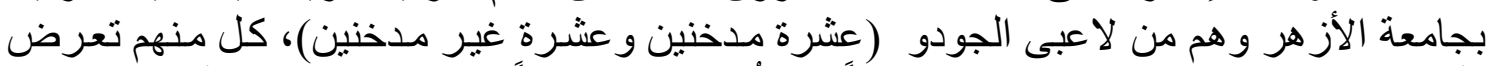

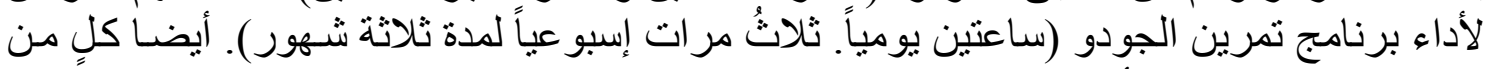

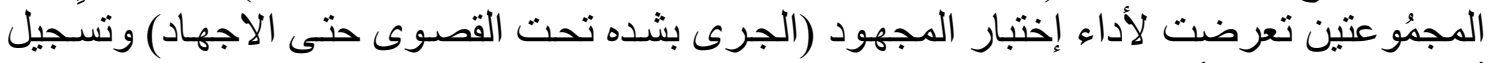

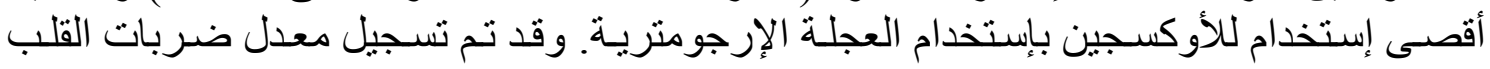

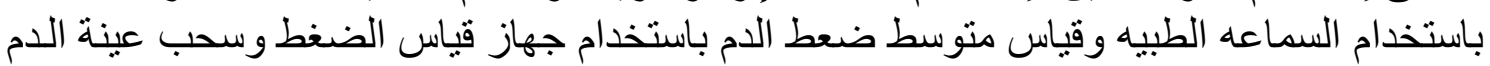

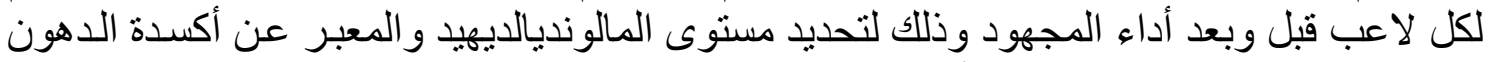

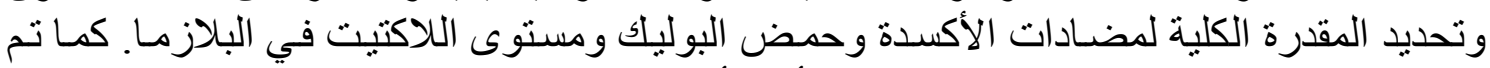

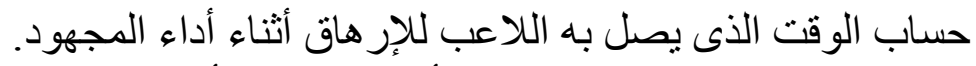
تم تحديد هذه القياسات قبل وبعد أداء البرنامج (أى بعد ثلاث شهور الثهر ). 


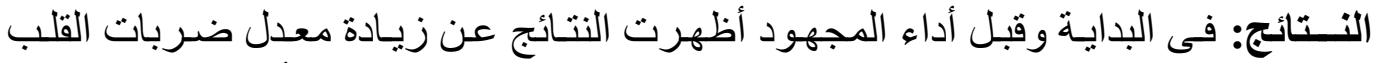

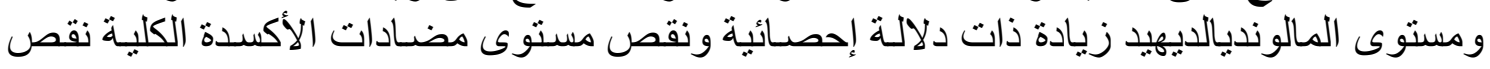

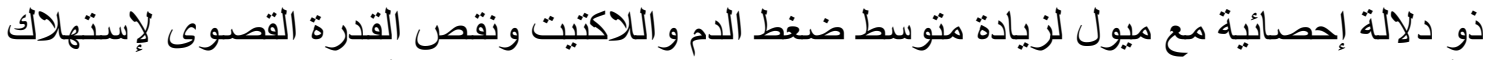

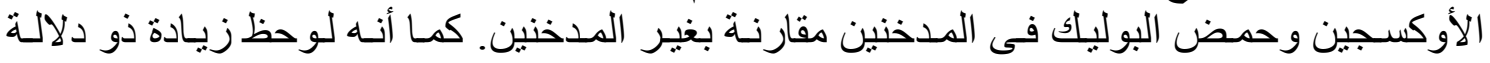

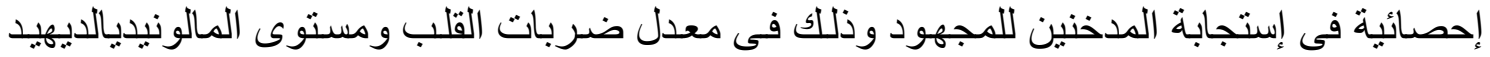
وحمض البوليك و اللاكتيت ونقص في المضات الكلية للأكسدة مقارنة بغير المدخنين سواء قبل ألبـ أداء

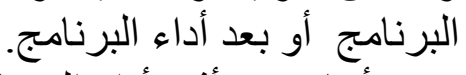

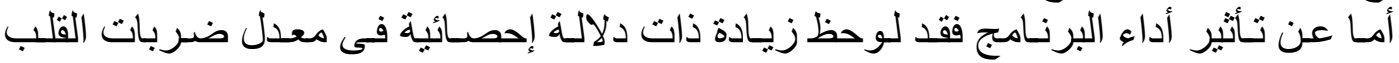

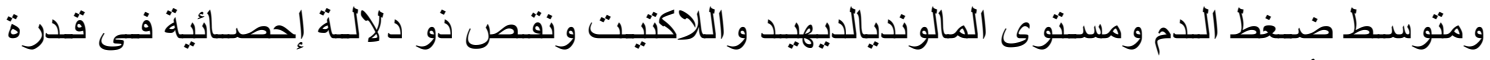

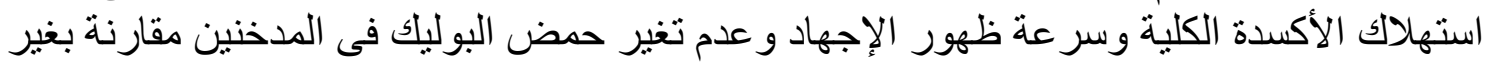

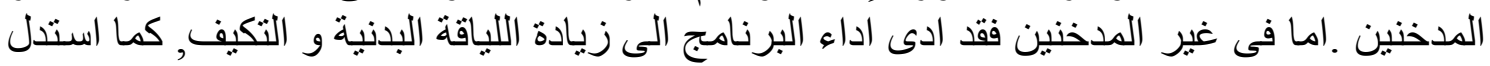

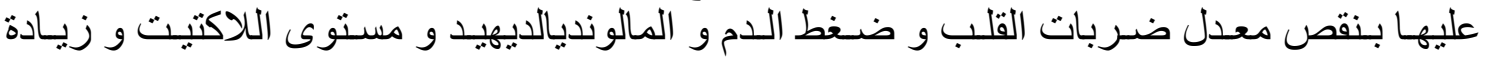

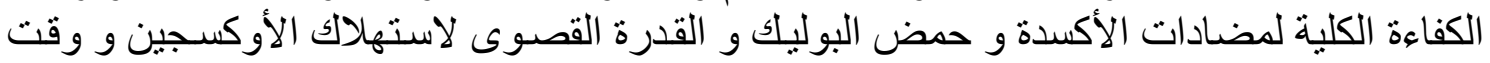
الوصول للإجهاد.

ونستخلص من ذللك أن للتنخين تأثتير سلبى على كفاءة الجهاز الدورى و اللياقة البدنية. كما

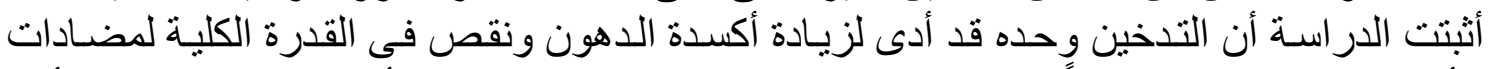

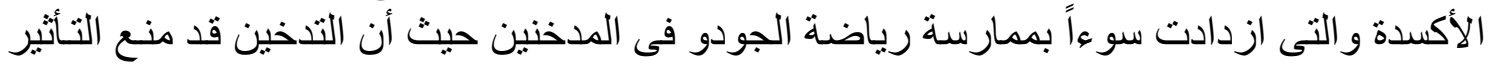

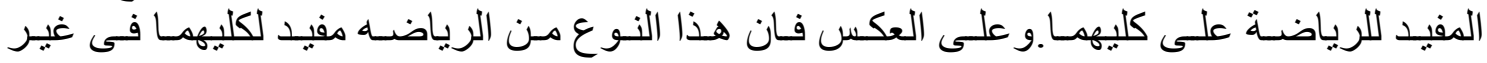

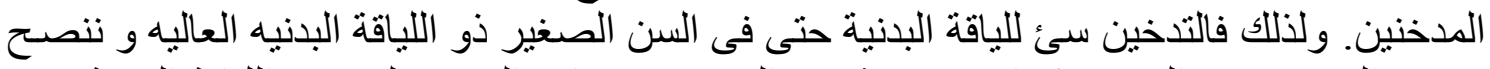
لاعبى الجودو بعدم التدخين كما نتصح بتشجيع المدخنين لإيقاف التدخين لتحنين لتحين اللياقة البدنية. 